\title{
Gamifying Questions by Adding Context in the Creative Development Marketing Research
}

\author{
Michał Ścibor-Rylski \\ Uniwersytet Warszawski, Wydział Zarządzania, Szturmowa 1/3, 02-678 Warszawa \\ mscibor-rylski@wz.uw.edu.pl \\ ORCID ID: https://orcid.org/0000-0002-0594-492X
}

Received: 10 June 2020/ Revised: 24 June 2020/ Accepted: 30 June 2020/ Published online: 9 November 2020

\begin{abstract}
Gamification is defined as using game design elements in non-gaming contexts: education, management, marketing and also market research. Gamified research tools help to increase respondents' engagement and obtain more in-depth results. Up till now the effects of gamifications were tested in the domains of brand strategy and consumer experience. The article shows the results of the experiment proving the effectiveness of a gamified approach to the qualitative advertisement testing. The experimental group with a narrative context added to a question regarding the first impression performed better than the control group with a standard task. Also gender differences were observed: the effect was valid only for men - there were no significant differences in the performance of women in both groups. Due to an uneven split of men and women and a small sample in general, this effect needs further examination.
\end{abstract}

JEL classification: M310; M370; M300

Keywords: gamification; market research; creative development

\section{INTRODUCTION}

The results of the experiments exploring the effectiveness of gamification in the marketing research (Puleston \& Sleep, 2011; Puleston \& Rintoul, 2012, Ścibor-Rylski, 2018; ŚciborRylski, 2019) prove that gamified methods adding context to the research questions increase the participants' performance. However, previous studies did not involve the real market research tasks. The researchers simply verified their hypotheses based on regular tasks focused on listing different items. This paper presents the results of the initial study designed to recreate a natural market research situation of the advertisement evaluation in the domain of creative development. The main goal of the research was to compare the participants' performance in two conditions: regular question and gamified one.

One of the most important market research indicators when it comes to the advertisement testing is the first impression. It is even more weighty in the qualitative approach, where the respondents fill out the individual questionnaire first and then they discuss the ad in the group. The first impressions written down on a sheet of paper make people hold to their opinions, avoiding yielding to group pressures. Classic psychological experiments (Sherif, 1935; Ash, 1951; Crutchfield, 1955) prove that people conform to group norms when they are put in an ambiguous 
situation - sitting among strangers and discussion marketing material fall under this category. The more thorough the individual opinion is, the better the effect on the further discussion. Hence the importance to motivate the participants to put an effort in writing the first impressions.

\section{LITERATURE REVIEW}

\subsection{The Importance of Games}

A huge variety of different forms, platforms and genres of games makes it very difficult to find common features that constitute a definition of game. McGonigal (2011) proposes four defining traits that are shared by all games. The role of all the other features is to reinforce and enhance these core elements:

- The goal, which is defined as a specific outcome we try to achieve. It gives the players a sense of purpose.

- The rules limit the participants on how they achieve the goal. Removing some obvious or typical behaviour from a game increases the creativity and triggers strategic thinking.

- The feedback, which tells the payers how far they are from achieving a goal. It provides motivation to carry on.

- Voluntary participation makes a game a safe and pleasurable activity.

Adding other, common game features like interactivity, narrative, rewards, competition or nice graphics results in the fact that playing games is fun. A game creates new quality in the ordinary and sometimes boring existence. Unlike real-life experience, a game gives an opportunity to test different solutions without any risk and also the gratification is immediate. Playing relaxes and amuses at the same time: people have fun, turn more spontaneous and unconstrained The major advantage of a game is one's involvement and sincerity of reactions and behaviour (Caillois, 1961).

Huizinga in Homo Ludens (1949) claims that playing is accompanied by a feeling of tension and joy. The involvement in a game evokes emotions that help people forget about dailiness. There are many interesting examples supporting this thesis in pop culture.

A great science-fiction visionary Philip K. Dick in his novel The Three Stigmata of Palmer Eldritch developed a concept of a game which was used by the unwilling colonists living in the horrible conditions on Mars. To make their life easier and prevent mutinies, the government invents a highly immersive game, which was based on playing a life of a Barbie alike doll named Perky Pat. The key to enjoy an alternative world was a strong, psychedelic drug called Can-D. This game become much more important for the colonists than their real, miserable life. A similar concept was used by Ernest Cline in his novel Ready Player One - a dystopian society on future, overcrowded and destroyed Earth is living mainly in an alternative, virtual world accessible by players using visors and haptic technology. Almost everything is possible in a game and people can fulfil their dreams impossible to realise in real life.

Pop culture reflects the needs and motivations of the society and such visions emphasise the importance of gaming for the human kind. According to the archetypical typology created by Mark and Pearson (2001), gaming experience fits the archetype of The Magician, whose main goal is to make dreams come true. The authors of "The Hero and the Outlaw. Building Extraordinary Brands Through the Power of Archetype" present different levels of the Magician archetype - there are magical moments and experiences of transformation on one level and the experience of flow on another. It fits perfectly Huizinga's (1949) observations regarding playing games. Also the idea of flow can be applied to games with reference to Cikszentmihalyi's definition (1990). The Hungarian psychologist describes the flow as a status between satisfaction and euphoria. It is activated by total devotion to a performed activity for the mere fun of doing it. 
Playing games impacts human cognitive and emotional performance. Playing a good game activates human key systems - motivation, attention, reward centre, emotion and memory. It also evokes a feeling of happiness which can be hardly achieved in such a compact way during the activities different from games. This is the reason for the enormous popularity of all types of games. In 2019 more than 100 million people watched the stream of "League of Legends" World Championship - one of the most popular online video games. During the final, the audience peaked at 44 million concurrent viewers (Webb, 2019). Also the popularity of board games is rising every year - the attendance of Spiel fair in Essen reflects this phenomenon. The worldwide biggest fair for board games attracted 147000 visitors in 2011 (Schymiczek, 2011) and the number was constantly growing each year reaching 209000 attendees in 2019 (Volkmann, 2019).

McGonigal (2011) cites sources showing that in the US 69\% of all heads of household play computer and video games and one out of four gamers is over the age of fifty. Another source shows that games are very popular among white collars $-61 \%$ of surveyed CEOs, CFOs and senior executives take their daily gaming breaks at work. The watchers of the Netflix series House of Cards certainly remember US president Frank Underwood played by Kevin Spacey, who regularly relaxes during a first-person-perspective video shooter.

\subsection{Gamification}

The positive effects of playing games commonly used in many non-gamified environments is called gamification and it is defined as using game design elements in non-gaming contexts (Deterding, Sicart, Nacke, O'Hara, \& Dixon, 2011).

Paharia (2013) indicates gamification as a crucial element of Loyalty 3.0 - the most advanced programme repairing the drawbacks of the loyalty actions based on simple transactional mechanisms known as Loyalty 1.0 and partially effective personalised marketing named Loyalty 2.0. Paharia argues that global trends make Loyalty 3.0 sine qua non in the modern business:

- Customers overwhelmed by the amount of information suffer from attention deficits and use heuristics when taking purchase decisions.

- Employees lack engagement, which leads to demotivation, frustration and the dissatisfaction of customers.

- We all live in times of overload - the number of used applications, the choice of products and services and the variety of their features make it impossible to focus on a brand without a true, carefully built engagement.

Beside motivation and big data, gamification is defined as a efficient tool to build engagement, activity and true loyalty of customers. The latter can be built if a client has an important reason to engage with a brand. A growing demand for experience is observed on the Polish market - already one in three Poles (34\%) claims that they would rather spend money on experiences than on material things (The Experience Advantage. 2019 Report Retail Banking, Kantar, 2019). Emotions and motivation play an important role in building experiences and gamification can help enhance both of these aspects of a truly customer-centric brand.

\subsection{Gamification in Marketing Research}

Gamified marketing makes customers more involved in brands and builds their loyalty. The concept of gamification used in marketing research serves different purposes. It improves involvement of participants and lets us obtain information which is not available in traditional approaches. Experiments show that tasks based on gaming mechanics provide wider, more elaborated results than the traditional ones, and also the research participants consider the process more enjoyable (e.g. Harrison, 2011; Puleston \& Sleep, 2011; Puleston \& Rintoul, 2012; Ścibor-Rylski, 2018; Ścibor-Rylski, 2019). 
Harrison (2011) reports positive effects of using a gamified approach in the research process - the respondents are more involved and open for sharing their thoughts. Games mechanisms induce a 'hot' behavioural condition when it is easier to reach true motivation and to reconstruct actual human behaviour - which is crucial especially while conducting qualitative marketing research. Involved in a pleasant activity, people are more sincere, engaged, creative and it is easier to discover their hidden beliefs and motivations. Moreover, the group process is smoother and the interaction more natural and efficient.

An example of fully gamified market research tools is „Our City” - a board game designed in Kantar Polska to examine customer experience adding a more in-depth component to the standard qualitative research processes using cognitive interviews (Geiselman et al., 1984). On the one hand - similarly to cognitive interviews - "Our City" allows for in-depth understanding of individual customer journeys: identification of its key stages and touch points. At the same time, it stimulates respondents' interaction and group dynamics, which boost creativity, indicating how customer experience can be improved in order to better suit the current and future market needs. Ścibor-Rylski (2020) presents the positive effects of the qualitative validation of "Our City" game's effectiveness as well as the results of the experiment proving the accuracy of the psychological premises of this tool.

Aside from "hard gamification", which makes the entire market research process a game, gamification can be applied in this field to make the questions more involving. It results in more elaborated responses and an increased level of completion. Puleston and Sleep (2011) emphasise the importance of design and ergonomic flow of research in the dropout reduction and making a survey more engaging experience for the consumer. They observed that applying fun or game-based mechanic resulted in very positive reactions from the respondents. People claimed that participating in the research was just more fun. Moreover, such a gamified approach stimulates respondents to be more effective.

Puleston (Puleston \& Sleep, 2011; Puleston \& Rintoul, 2012) provides a thorough overview of different game-based elements successfully used in market research surveys to increase the respondents' effectiveness and involvement by extending the respondent's concentration spans. Numerous experiment results were replicated by Ścibor-Rylski $(2018,2019)$. In one of them, the participants of the control group were naming their favourite Olympic disciplines. The gamified group was asked to imagine that they were responsible for TV broadcasting of the Olympic Games and their job was to plan the broadcast based on the disciplines they would like to watch. The results of this study proved that adding context significantly increased the average number of listed disciplines when compared to the regular approach.

The gamified approach provides invaluable help in the process of designing a quantitative survey questionnaire or some simple qualitative tasks for the respondents. The next chapter presents the results of the experiment designed to prove the influence of gamified tasks on participants' performance using the context change in the natural market research setup.

As a result of the literature review presented above, a hypothesis was formulated:

Hypothesis: employing a gamification technique based on adding a context to a question improves performance of research participants.

\section{RESEARCH METHODS}

I conducted the experimental study on 59 students of Management Faculty of the University of Warsaw (38 women and 21 men) split into two groups:

- control (no gamified techniques were used),

- experimental (with a gamified question - context added). 
The participants were asked to watch a commercial - a TV advertisement of Castorama - DiY market (Castorama Polska, 2018). The ad lasted 45 seconds and its plot focused of the romantic relationship of two young people living next door. The role of the brand was to inspire the male character to accomplish a project - create a roof garden that helped him charm his female neighbour. The story was emotional and there were many humouristic scenes.

After watching the commercial, the participants were asked to fill out the form with only one question. Its content was different in the respective groups.

The control group was simply asked about their first impressions. They received the following instruction:

"Watch the commercial and write down what do you think of it."

In the experimental group, a context was introduced to the question. They received the following instruction:

"Imagine you work for an advertisement agency and you are working on a new campaign. Your biggest rival working for a competitor's brand has just created a new ad-somehow you managed to watch it before the official premiere. You need to react as soon as possible to design a relevant commercial as a response and not to fall behind. You want to share your thoughts with the creative team and your management. Watch the commercial and write down what do you think of it."

No time limit was imposed. The next subchapter presents the results of the comparison between two groups. The indicator used to measure the performance was the word count in each answer.

\section{RESULTS}

The average word count of the answers was calculated in each group. The experimental group used more words $(M=47.79 ; S D=19.46)$ compared to the control group $(M=37.77 ; S D=18.01)$.

T-test was used to analyse the significance of the difference. It revealed a statistically significant difference and the average effect size: $t(57)=2.05 ; p<0.05 ; d=0.53$. The results are presented in Chart 1.

\section{Chart 1}

Differences in the average number of words used by control and experimental groups

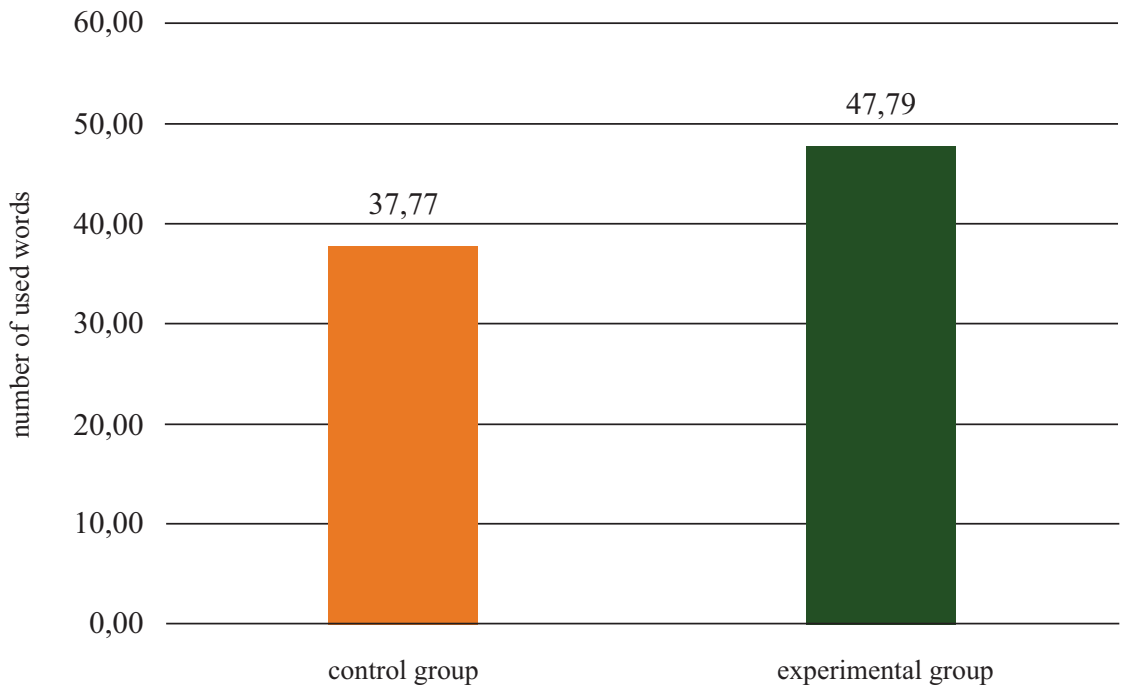


The group with the narrative gamification technique using context generated significantly longer answers than the control group. The hypothesis has been confirmed.

Additionally, the effect of the gender was calculated. Due to the uneven number of men and women in the research and a small sample in general, the results of this analysis are just illustrative and the observed effect needs further examination and verification. The gender split in each group is presented in the table below:

Table 1

Gender split in control and experimental groups

$\begin{array}{lcc} & \text { Control group } & \text { Experimental group } \\ \text { Men } & \mathrm{N}=9 & \mathrm{~N}=12 \\ \text { Women } & \mathrm{N}=22 & \mathrm{~N}=16\end{array}$

A two-way analysis of variance was used to test the interaction of group and gender. The interaction effect turned out to be significant with the average effect size: $F(1.55)=5.52 ; p<0.05$; $\eta^{2}=0.09$. The outcome is presented in Chart 2 .

\section{Chart 2}

Interaction of group and gender.

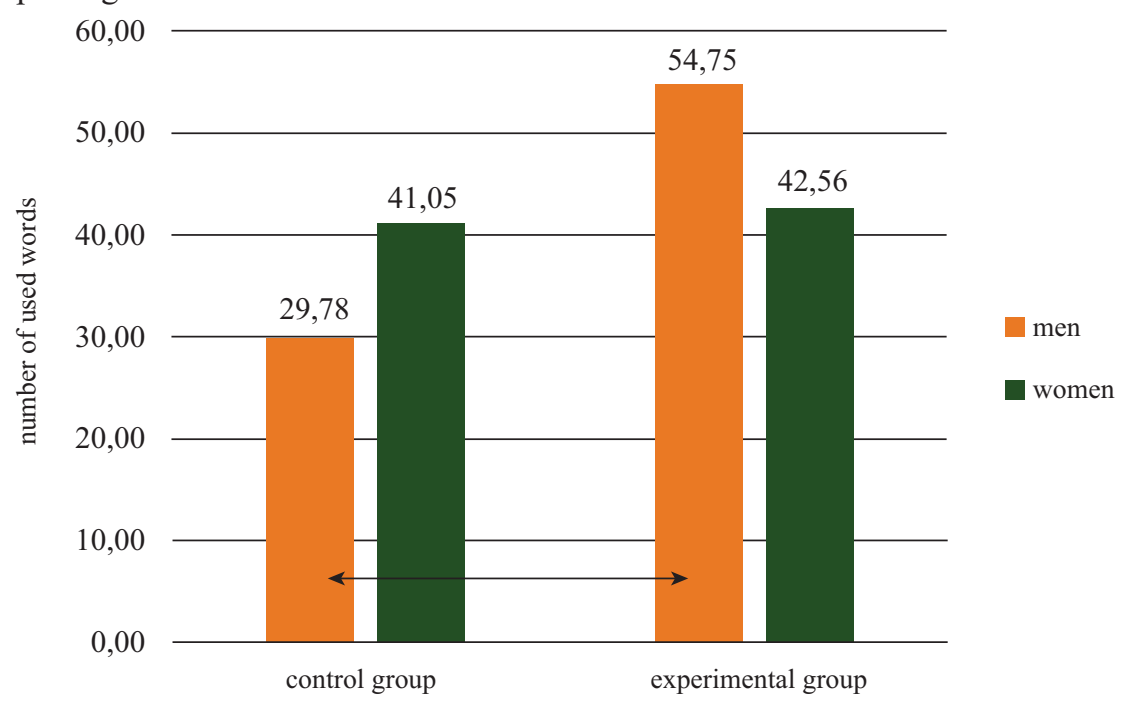

The only significant simple effect is the difference between men in the control and experimental groups as:

$F(1.55)=9.73 ; p<0.01 ; \eta^{2}=0.15$. There was no difference between groups in the case of women.

\section{RESULTS DISCUSSION}

The analysis described in this chapter has confirmed the hypothesis. Gamified tasks stimulate respondents and provide more elaborated answers. People use more words to describe their first impressions after watching a TV commercial if the question has added context - a narrative introduction allowing the participants to get into the given character. Such a result has great implications both for qualitative and quantitative marketing research. In the focus group, when filling out an individual response form after watching a commercial, participants can be more 
effective and then they have more data to use during discussion. Also deeper, more elaborated statements help the analysis - first impressions are crucial when it comes to understanding the power of a commercial: they influence the responses and behaviour that follow (Hallward, 2005).

An additional analysis showed that the positive effect of a gamified question is valid only for men. This phenomenon needs further testing - the research sample was rather small and also the gender split was not even. Certainly, a replication of the experiment is required with a gender variable added as a controlled factor. If the effect persists, it might open new research areas in the field of the role of gamification in advertisement testing. There are numerous studies showing the female superiority in verbal skills (e.g. Hyde \& Linn, 1988). It might be a cause of the observed effect - maybe gamification in the form of adding context helps men to achieve the verbal level of women when it comes to writing down their first impressions after seeing a very emotive commercial? The gender difference in the experimental group was not significant, but it seems that it might be the effect of a small sample. The layout of the results suggests that men might be even more effective than women when confronted with the gamified question. Certainly, a further examination of this phenomenon is required.

\section{CONCLUSIONS}

The described experiment successfully replicates the previous results proving the effectiveness of gamified techniques. Numerous experiments have proven that adding game elements enhances the results of the research in the fields of brand strategy and consumer experience (Ścibor-Rylski $2018,2019,2020)$. Now the effect was observed in the domain of creative development - the natural market research situation of advertisement testing. The implications of the described experiment are vast. Changing the context of the first impression questions might be a way to achieve better material for analysis as well as to avoid participants falling under group pressures in further discussion. Currently, further research is planned to replicate the effect. Also an online version of the experiment is being developed. Nowadays, market research companies move a significant part of their qualitative research to the internet platforms. Focus groups using MS Teams or Zoom platforms supported by Miro or Mural applications are becoming a natural research environment. Testing the previously observed effects online seems essential to fully understand how gamification works in the marketing research.

\section{References}

Asch, S.E. (1951). Effects of group pressure upon the modification and distortion of judgments. In H. Guetzkow (Ed.), Groups, leadership and men. Pittsburg, PA: Carnegie Press.

Crutchfield, R. (1955). Conformity and character. American Psychologist, 10, 191-198.

Caillois, R. (1961). Man, play and games. New York: Free Press of Glencoe.

Becker, S., Goldstein, D., \& Sweeney, T. (2013). Does a gamified approach provide greater insight?. ARF Experiential Learning, Re:Think conference.

Castorama Polska (2018, March 19). Potrzeby inspirują do zmian - wiosenny ogród na dachu [Video]. YouTube. https://www.youtube.com/watch?v=uzpPuOSfaqk

Csikszentmihalyi, M. (1990). Flow. New York: Harper and Row.

Deterding, S., Sicart, M., Nacke, L.E., O’Hara, K., \& Dixon, D. (2011). Gamification: Using game design elements in non-gaming contexts. Proceedings of CHI EA 2011. Vancouver, BC, Canada. ACM, 2425-2428.

Geiselman, R.E., Fisher, R.P., Firstenberg, I. Hutton, L.A., Sullivan, S.J., Avetissain, I.V., \& Prosk, A.L. (1984). Enhancement of eyewitness memory: An empirical evaluation of the cognitive interview. Journal of Police Science and Administration, 12(1), 74-80.

Hallward, J. (2005). Emotions are the equivalent of first impressions. Ipsos Ideas, 3-5.

Harrison, P. (2011). The researchification of games: Adopting a game designer's approach to market research. ESOMAR Congress Miami. 
Huizinga, J. (1949). Homo Ludens: A study of the play-element in culture. London: Routledge \& Kegan Paul.

Hyde, J.S., \& Linn, M.C. (1988). Gender differences in verbal ability: A meta-analysis. Psychological Bulletin, 104(1), 53-69.

Mark, M., \& Pearson, C.S. (2001). The hero and the outlaw. Building extraordinary brands through the power of archetypes. New York: McGraw-Hill.

McGonigal, J. (2011). Reality is broken. Why games make us better and how they can change the world. London: Jonathan Cape.

Paharia, R. (2013). Loyalty 3.0: How to revolutionize customer and employee engagement with big data and gamification. New York: McGraw-Hill.

Puleston, J., \& Rintoul, D. (2012). Can survey gaming techniques cross continents? Examining cross cultural reactions to creative questioning techniques. ESOMAR Congress Shanghai.

Puleston, J., \& Sleep, D. (2011) The game experiments: Researching how game techniques can be used to improve the quality of feedback from online research. ESOMAR Congress Amsterdam.

Schymiczek, M. (2011, October 23). 147000 Besucher bei der Spielemesse in Essen. WAZ. Retrieved from https:// www.waz.de/staedte/essen/147-000-besucher-bei-der-spielemesse-in-essen-id5190519.html

Sherif, M. (1935). A study of some social factors in perception. Archives of Psychology, 27(187).

Ścibor-Rylski, M. (2018). Gamification as an effective method in the modern market research. Marketing $i$ Rynek, $10 / 2018,36-44$.

Ścibor-Rylski, M. (2019). Gamification - The key to in-depth exploration of consumer behaviour in market research. Annales Universitatis Mariae Curie-Skłodowska, sectio H-Oeconomia, 53(1), 119-128. DOI: $10.17951 / h .2019 .53 .1 .119-128$

Ścibor-Rylski, M. (2020). Grywalizacja w służbie badań doświadczeń konsumenckich. In K. Mazurek-Łopacińska \& M. Sobocińska (Eds.), Badania marketingowe wobec nowych trendów w otoczeniu. Wrocław: Wydawnictwo Uniwersytetu Ekonomicznego we Wrocławiu.

The Experience Advantage. 2019 Report Retail Banking. (2019). Kantar.

Volkmann, A. (2019, October 27). SPIEL'19 endet mit Besucherrekord: Über 200.000 Fans feiern Spiele in Essen. Spielpunkt. Retrieved from https://spielpunkt.net/2019/10/27/ spiel19-endet-mit-besucherrekord-ueber-200-000-fans-feiern-spiele-in-essen/

Webb, K. (2019, December 18). More than 100 million people watched the 'League of Legends' World Championship, cementing its place as the most popular esport. Business insider. Retrieved from https://www.businessinsider. com/league-of-legends-world-championship-100-million-viewers-2019-12?IR=T 